\title{
Prevalence of asymptomatic bacteriuria among low risk pregnant women attending antenatal care clinic in tertiary hospital: a cross sectional study
}

\author{
Esraa Badraan', Ahmed M. Abbas ${ }^{1 *}$, Moustafa Kamel², Mohammed Z. Abdelrahman³, \\ Ahmed A. Youssef ${ }^{1}$, Mohammed A. Youssef ${ }^{1}$
}

\author{
${ }^{1}$ Department of Obstetrics and Gynecology, Faculty of Medicine, Assiut University, Egypt \\ ${ }^{2}$ Department of Obstetrics and Gynecology, Tahta General Hospital, Sohag, Egypt \\ ${ }^{3}$ Department of Clinical Pathology, Faculty of Medicine, Assiut University, Egypt
}

Received: 26 April 2019

Accepted: 01 June 2019

\section{*Correspondence: \\ Dr. Ahmed M. Abbas, \\ E-mail: bmr90@ @otmail.com}

Copyright: (C) the author(s), publisher and licensee Medip Academy. This is an open-access article distributed under the terms of the Creative Commons Attribution Non-Commercial License, which permits unrestricted non-commercial use, distribution, and reproduction in any medium, provided the original work is properly cited.

\begin{abstract}
Background: The current study aims to identify the prevalence of asymptomatic bacteriuria among low-risk pregnant women attending the antenatal care clinic of tertiary University Hospital and to detect the most common causative organisms.

Methods: A prospective cross-sectional study conducted at a tertiary University Hospital in the period between $1^{\text {st }}$ November 2017 and $31^{\text {st }}$ June 2018. All eligible women attending the outpatient clinic for antenatal care were approached to participate in the study. The recruited women were assessed through detailed history and clinical examination. Urine samples were taken for culture and sensitivity within two hours, in order to avoid bacterial multiplication. Urine culture and antibiotic sensitivity test were done.

Results: The study included 250 women. The mean age of included women was $25.89 \pm 5.49$ (18-42 years). The urine analysis results showed that $32 \%$ of cases had pus cells $>5$ per high power field and $10.4 \%$ of cases have protein $(+)$. Casts were present in $0.8 \%$ of cases. RBCs $>5$ per high power field were present in $4.8 \%$ of cases. ASB is defined as urine culture with more than 100,000 colony forming unit; this was present in 30 cases. This indicates that the prevalence of ASB among studied cases was $12 \%$. Enterococcus was the most prevalent organism as it was present in $36.7 \%$ among positive cases. Antibiotic sensitivity test was performed to the growing organisms indicated that teicoplanin, imipenem, cefoxitin, cefotaxime + clavulanic acid, Entrapenem, and trimethoprim + sulfamethoxazole are the most effective antibiotics against the most common organisms causing asymptomatic bacteriuria.

Conclusions: The prevalence of asymptomatic bacteriuria among low-risk pregnant women is about $12 \%$. Urine culture for asymptomatic bacteriuria should be the standard of care for evaluation of pregnant patient during antenatal care as regard presence or absence of UTI.
\end{abstract}

Keywords: Bacteriuria, Pregnancy, Urine analysis, Urine culture, Urinary tract infections

\section{INTRODUCTION}

Urinary tract infections (UTIs) commonly occur during pregnancy due to morphological and physiological changes that take place in the genitourinary tract. UTIs are two types symptomatic and asymptomatic. Asymptomatic bacteriuria (ASB) is defined as the presence of actively multiplying bacteriuria which is 
greater than $105 / \mathrm{ml}$ of urine within the urinary tract without symptoms of UTI. Asymptomatic bacteriuria can be found in both pregnant and non-pregnant women. ${ }^{1}$

Prevalence of ASB was found to be $2-11 \%$ in pregnant women. Pregnancy enhances the progression from ASB to symptomatic bacteriuria which could lead to acute pyelonephritis in $10-50 \%$ of cases, preeclampsia, anaemia, low birth weight of foetus, intrauterine growth restrictions, preterm labour and premature rupture of membranes. ${ }^{2}$ ASB is amicrobial diagnosis which is based on isolation of a specified quantitative count of bacteria in a specimen of urine which is properly collected from pregnant women who does not have any symptoms or signs. Thus, urine culture is the gold standard screening technique for ASB which occur during pregnancy. ${ }^{3}$ Implicated bacteria include escherichia coli, staphylococcus aureus, providencia species and klebsiella species. ${ }^{4}$ The relatively high prevalence of ASB during pregnancy, the significant consequences faced by women and their pregnancies and the ability to avoid undesired outcomes with treatment justify screening and treatment of ASB in pregnancy. ${ }^{5}$

Therefore, the current study aims to identify the prevalence of ASB among low-risk pregnant women attending the antenatal care clinic of tertiary University Hospital and to detect the most common causative organisms.

\section{METHODS}

The current study was a prospective cross-sectional study conducted at a tertiary University Hospital in the period between the $1^{\text {st }}$ November 2017 and $31^{\text {st }}$ June 2018 . The Institutional Ethical Review Board approved the study protocol. All women who participated in the study signed a written informed consent before inclusion.

\section{Inclusion criteria}

- All eligible women attending to the outpatient clinic for antenatal care were approached to participate in the study.

\section{Exclusion criteria}

- Pregnant women who were on antibiotic or had been on antibiotic at least two weeks prior to presentation.

- Pregnant women with symptomatic UTI (dysuria, increased frequency of micturition, fever with chills, suprapubic pain)

- Multiple pregnancies.

- Pregnancy induced hypertension and diabetes mellitus.

- Pregnant women with congenital renal anomalies and urinary stones.
The recruited women were assessed through detailed history is taking and clinical examination. Urine samples were collected as follows:

- Sitting position

- Separation the two labia

- Drying of urethra by clean towel from front backwards

- Passing amount of urine into the toilet and hold

- Putting wide-mouthed sterile capped empty container and having the midstream sample. ${ }^{6}$

The samples were transported to clinical pathology department lab of for culture and sensitivity within two hours in order to avoid bacterial multiplication. If delay more than two hours was anticipated, urine was refrigerated at 2 to $8^{\circ} \mathrm{C}$ for 24 hours.

\section{Macroscopically}

All samples which were turbid or red (pus or blood cells) were excluded. Urine culture was done with $0.001 \mathrm{ml}$ of well mixed urine delivered by a sterile calibrated wire loop and plated on UriSelect media, which were incubated aerobically at 35 to $37^{\circ} \mathrm{C}$ for 24 hours. The loop was held in a vertical position, inserted just below the surface of the urine. Streaked full of urine down the center of the plate. Without changing or reflaming the loop, it was streaked many times at right angles over the original streak, covering the entire plate. No restreaking over already streaked areas was done. This procedure was done for both plates (with different cultures) by separate sterile standardized loops.

Samples were visualized after 24 hours, if no growth in 24 hours incubation was done. After that (sum of 48 hours) no growth meant negative sample each significant isolate was identified by colonial morphology, colonies color (escherichia coli-pink, enterococcus-turquoise, klebsiella pneumonia-blue purple, staphylococcus aureus-white) and biochemical reactions according to standard procedure.

\section{Different types in results of culture}

- A urine culture was defined as positive if the culture showed significant bacteriuria $\left(10^{5}\right.$ colony forming units/ml of urine)

- A culture was defined as contaminated if there was a mixed culture of any density or if there was a pure culture of less than $10^{5}$ colony forming units/ml and cultures were repeated

- Cultures in which there was no growth of bacteria were classed as negative.

Colony count was done by naked eye and the actual number of colonies was calculated by multiplied colony count by 1000 .

\section{Antibiotic sensitivity test}


With sterile standardized loop, 3-5 well isolated colonies of similar appearance were touched, emulsified in 3-4 ml of sterile physiological saline in a tube and immediately mixed by the same loop until it came turbid. A sterile swab was used to inoculate the sample on a new culture plate (Muller Hinton agar) after removal of excess fluid by pressing and rotating the swab against the tube wall. The swab was then streaked evenly over the surface of the medium in three directions with rotating the plate approximately 60 degrees to ensure even distribution. The plate was left in place for 3-5 minutes to allow even distribution and surface of the plate to dry. A sterile forceps was used to put the antibiotic discs evenly distributed on the plate $(25 \mathrm{~mm}$ from disc to disc and $15 \mathrm{~mm}$ from the edge of the plate).

Within the 15 minutes of applying the discs, plates were inverted and incubated aerobically at $37^{\circ} \mathrm{C}$ for $16-18$ hours. A ruler was used to estimate the inhibition zone in $\mathrm{mm}$ (the end point of inhibition is where growth starts).

\section{Statistical analysis}

The data were collected and entered into a Microsoft Access database then analyzed using the Statistical Package for Social Science (SPSS Inc., Chicago, version 22). Quantitative data was presented in terms of mean \pm SD then compared using a Student's t-test. Qualitative variables were presented as frequency and percentage. Chi-square test was used for comparison between groups. For analysis, $\mathrm{p}<0.05$ was considered to be significant.

\section{RESULTS}

The study included 250 women. The mean age of included women was 25.89 \pm 5.49 (18-42 years). There was $22.4 \%$ of the study participants primigravida and $77.6 \%$ were multigravida. As regard deliveries, $42 \%$ of cases were delivered normal and $44.4 \%$ was delivered by Caesarean section (CS). The urine analysis results show that $32 \%$ of cases have pus cells $>5$ per high power field and $10.4 \%$ of cases have protein $(+)$. Casts were present in $0.8 \%$ of cases. RBCs $>5$ per high power field were present in $4.8 \%$ of cases. ASB is defined as urine culture with more than 100,000 colony forming unit; this was present in 30 cases. This indicates that the prevalence of ASB among studied cases was $12 \%$.

Table 1: Description of different organisms' growth among positive cultures.

\begin{tabular}{|lll|}
\hline Organisms & $(\mathrm{N}=30)$ & $\%$ \\
\hline Enterococcus & 11 & 36.7 \\
\hline E.coli & 10 & 33.3 \\
\hline Klebsiella & 4 & 13.3 \\
\hline S. aureus & 2 & 6.7 \\
\hline S.epidermidis & 1 & 3.3 \\
\hline S. haemolyticus & 1 & 3.3 \\
\hline S. agalactiae & 1 & 3.3 \\
\hline
\end{tabular}

The results of culture in cases of ASB are shown in Table 1. Enterococcus was the most prevalent organism as it was present in $36.7 \%$ among positive cases. The second commonly isolated organism was $E$. coli as was present in $33.3 \%$ among positive cases. Antibiotic sensitivity test was performed to the growing organisms and showed in Table 2. This table indicates that teicoplanin, imipenem, cefoxitin, cefotaxime + clavulanic acid, Entrapenem, and trimethoprim + sulfamethoxazole are the most effective antibiotics against the most common organisms causing asymptomatic bacteriuria.

Table 2: Antibiotic sensitivity to culture positive organisms.

\begin{tabular}{|c|c|c|}
\hline Antibiotics & $(\mathbf{N}=30)$ & $\%$ \\
\hline Teicoplanin & 14 & 46.7 \\
\hline Iminepem & 11 & 36.7 \\
\hline Entrapenem & 10 & 33.3 \\
\hline Cefotaxime+clavunic acid & 9 & 30.0 \\
\hline Cefoxitin & 9 & 30.0 \\
\hline Trimethoprim+sulfamethoxazole & 9 & 30.0 \\
\hline Cefotaxime & 8 & 26.7 \\
\hline Neomycin & 8 & 26.7 \\
\hline Norfloxacin & 8 & 26.7 \\
\hline Cefaclor & 8 & 26.7 \\
\hline Lomefloxacin & 8 & 26.7 \\
\hline Aztreonam & 7 & 23.3 \\
\hline Doxycycline & 7 & 23.3 \\
\hline Ceftazidime & 7 & 23.3 \\
\hline Cefixime & 5 & 16.7 \\
\hline Oxacilin & 5 & 16.7 \\
\hline Cefepime & 5 & 16.7 \\
\hline Kanamycin & 5 & 16.7 \\
\hline Levofloxacin & 5 & 16.7 \\
\hline Gentamycin & 5 & 16.7 \\
\hline Ciprofloxacin & 5 & 16.7 \\
\hline Nitrofurantoin & 5 & 16.7 \\
\hline Cefodizime & 4 & 13.3 \\
\hline Linzolid & 4 & 13.3 \\
\hline Amikacin & 4 & 13.3 \\
\hline Piperacillin & 3 & 10.0 \\
\hline Lincomycin & 3 & 10.0 \\
\hline Ampicllin & 3 & 10.0 \\
\hline Tetracycline & 3 & 10.0 \\
\hline Ceftrixone & 3 & 10.0 \\
\hline Clindamycin & 3 & 10.0 \\
\hline Rifampicin & 3 & 10.0 \\
\hline Vancomycin & 3 & 10.0 \\
\hline Meropenem & 3 & 10.0 \\
\hline Azithromycin & 2 & 6.7 \\
\hline Cephalothin & 2 & 6.7 \\
\hline Erythromycin & 2 & 6.7 \\
\hline Benzylpenicillin & 2 & 6.7 \\
\hline
\end{tabular}




\begin{tabular}{ccc} 
Penicillin & 1 & 3.3 \\
\hline
\end{tabular}

Table 3: Relationship between bacterial cell count and personal data.

\begin{tabular}{|c|c|c|c|c|c|}
\hline \multirow{3}{*}{$\begin{array}{l}\text { Personal } \\
\text { data }\end{array}$} & \multicolumn{4}{|c|}{ Bacterial cell count } & \multirow{3}{*}{$P$ value } \\
\hline & \multicolumn{2}{|c|}{$<100,000$} & \multicolumn{2}{|c|}{$\geq 100,000$} & \\
\hline & No. & $\%$ & No. & $\%$ & \\
\hline \multicolumn{6}{|l|}{ Age (years) } \\
\hline$<25$ & 96 & 87.3 & 14 & 12.7 & \\
\hline 25 to 29 & 77 & 92.8 & 6 & 7.2 & 0.173 \\
\hline$\geq 30$ & 47 & 82.5 & 10 & 17.5 & \\
\hline \multicolumn{6}{|l|}{ Residence } \\
\hline Rural & 160 & 86.5 & 25 & 13.5 & \\
\hline Urban & 60 & 92.3 & 5 & 7.7 & 0.214 \\
\hline \multicolumn{6}{|l|}{ Occupation } \\
\hline Not working & 199 & 87.7 & 28 & 12.3 & \\
\hline Working & 21 & 91.3 & 2 & 8.7 & 0.861 \\
\hline \multicolumn{6}{|c|}{ Passive smoking } \\
\hline Non-smoker & 142 & 90.4 & 15 & 9.6 & \\
\hline Smoker & 78 & 83.9 & 15 & 16.1 & 0.122 \\
\hline \multicolumn{6}{|l|}{ BMI } \\
\hline Normal & 122 & 86.5 & 19 & 13.5 & \\
\hline Overweight & 61 & 87.1 & 9 & 12.9 & \\
\hline Obese & 37 & 94.9 & 2 & 5.1 & 0.353 \\
\hline
\end{tabular}

Table 4: Relationship between bacterial cell count and obstetrical data.

\begin{tabular}{|c|c|c|c|c|c|}
\hline & \multicolumn{4}{|c|}{ Bacterial cell count } & \multirow{3}{*}{$P$ value } \\
\hline & \multicolumn{2}{|c|}{$<100,000$} & \multicolumn{2}{|c|}{$\geq 100,000$} & \\
\hline & No. & $\%$ & No. & $\%$ & \\
\hline \multicolumn{6}{|c|}{ Number of pregnancies } \\
\hline Primigravida & 47 & 83.9 & 9 & 16.1 & \multirow{2}{*}{0.287} \\
\hline Multigravida & 173 & 89.2 & 21 & 10.8 & \\
\hline \multicolumn{6}{|c|}{ Number of normal deliveries } \\
\hline No & 129 & 89 & 16 & 11 & \multirow{2}{*}{0.581} \\
\hline Yes & 91 & 86.7 & 14 & 13.3 & \\
\hline \multicolumn{6}{|c|}{ Number of caesarean deliveries } \\
\hline No & 120 & 86.3 & 19 & 13.7 & \multirow{2}{*}{0.363} \\
\hline Yes & 100 & 90.1 & 11 & 9.9 & \\
\hline \multicolumn{6}{|c|}{ Number of abortions } \\
\hline No & 152 & 85.4 & 26 & 14.6 & \multirow{2}{*}{$0.046^{*}$} \\
\hline Yes & 68 & 94.4 & 4 & 5.6 & \\
\hline \multicolumn{6}{|l|}{ No of ectopic } \\
\hline No & 215 & 87.8 & 30 & 12.2 & \multirow{2}{*}{1.00} \\
\hline Yes & 5 & 100 & 0 & 0 & \\
\hline \multicolumn{6}{|c|}{ Number of preterm deliveries } \\
\hline No & 197 & 87.9 & 27 & 12.1 & \multirow{2}{*}{1.00} \\
\hline Yes & 23 & 88.5 & 3 & 11.5 & \\
\hline \multicolumn{6}{|c|}{ Number of living offspring } \\
\hline No & 65 & 86.7 & 10 & 13.3 & \multirow{2}{*}{0.671} \\
\hline Yes & 155 & 88.6 & 20 & 11.4 & \\
\hline \multicolumn{6}{|l|}{ Trimester } \\
\hline First & 32 & 86.5 & 5 & 13.5 & 0.883 \\
\hline
\end{tabular}

\begin{tabular}{|lcrll|}
\hline Second & 60 & 89.6 & 7 & 10.4 \\
\hline Third & 128 & 87.7 & 18 & 12.3 \\
\hline
\end{tabular}

The total studied cohort (250 patients) were divided into two groups these who had bacterial cell count $>100,000$ and those who had bacterial cell count $<100,000$. Personal data and obstetric data were compared to outline possible risk factors for asymptomatic bacteriuria. No statistical difference between both groups as regard age, residence, occupation, passive smoking and body mass index (Table 3).

Table 4 indicates that there was no statistical difference between both groups as regard number of pregnancies, number of normal deliveries, number of cesarean sections, number of ectopic pregnancies, number of preterm deliveries and trimester of pregnancy. Asymptomatic bacteriuria was higher among patients who have no abortions with statistical significance.

\section{DISCUSSION}

Asymptomatic bacteriuria is a major risk factor for the development of UTIs. During pregnancy, many changes occur in the structure and function of the urinary tract that predispose pregnant women to upper UTI. ${ }^{7}$ During pregnancy, ASB is not considered benign, because pregnancy induces stasis and accordingly increases the risk for pyelonephritis. Controversy exists regarding the association between ASB during pregnancy and adverse perinatal outcome, including preterm deliveries and lowbirthweight (LBW). However, meta-analysis of cohort studies showed that untreated ASB during pregnancy significantly increased rates of $\mathrm{LBW}$ and preterm delivery. ${ }^{8}$ Because of the crucial role of ASB in pregnancy in the causation of acute pyelonephritis, there is not much dispute in the recommendation that all pregnant women should be screened for bacteriuria on their first prenatal visit. There are also attendant morbid consequences for the fetus such as prematurity and low birth weight if the mother is left untreated, whether or not she develops overt urinary tract infection later in her pregnancy. ${ }^{9}$

This makes detection of the condition is the most important then appropriate antimicrobial intervention should be initiated immediately for those found positive. The diagnosis of ASB is based upon quantitative urine culture of a midstream clean-catch specimen with $>100,000 \mathrm{CFU} / \mathrm{ml}$ urine and an isolate of a single uropathogen in a patient presenting with no symptoms. ${ }^{10}$ Most specimens contaminated during collection contain $<100,000 \mathrm{CFU} / \mathrm{ml}$. Most studies utilized a single specimen as basis for the diagnosis, only one study required two consecutive specimens. There was no significant variation between the studies that based their diagnosis on a single positive urine culture and the study using two consecutive positive urine cultures as its basis for diagnosis. ${ }^{11}$ 
Consequences of failure to detect the condition and missing treatment are more crucial than treating those who actually do not have the infection, and also requesting the patient to come back for another specimen collection for urine culture and subsequent follow-up of its result would increase the risk of patients being lost to follow-up and their receiving no treatment at all. With these considerations, the requirement of two consecutive positive cultures should be re-evaluated. Veri and colleagues found a three times higher prevalence among booked Caucasian women compared to their Bangladeshi counterparts at Royal London hospital i.e. $6.3 \%$ compared to $2 \%$ respectively. They attributed to difference in clothing and practice of ablution after defecation and micturition. ${ }^{12}$ Among 250 women included in our study, 30 women had true culture bacteriuria giving a prevalence of $12 \%$. As a comparison with the previous studies, this prevalence falls within the $2-12 \%$ range in the population quoted in epidemiological studies. ${ }^{13}$ Unco et al, had a study in Turkey involving 270 women up to 32 weeks and had prevalence $9.3 \%$. $^{2}$ Abdullah and Al-Mosleh, conducted a study in United Arab Emirates involved 505 women where the prevalence was $4.8 \% .^{7}$ Labi et al, reported a prevalence of ASB was 5.5\%. ${ }^{14}$ However, other studies showed much higher prevalence of ASB including Akinloye et al, in his study in Nigeria included 300 women screened for bacteriuria and found $21 \%$ prevalence. ${ }^{15}$ The prevalence of ASB was $14.2 \%$ in Ayoyi et al, study. ${ }^{16}$ This variation is explained by the population characteristics, the screening methodology and definition of bacteriuria. The microbiology of bacteriuria in our study showed that Enterococcus was the most common pathogen (36.7\% of the positive cultures) followed by E.coli and Klebsiella. These results agree with Labi et al, in his study in Ghana found that $26.7 \%$ of the positive cultures were infected by Enterococcus. ${ }^{14}$ Molina et al, reported that E.coli and proteus mirabilis were the most frequent isolated bacteria in positive ASB cases. ${ }^{17}$ Anku G et al, reported that most of gram positive organisms were sensitive to teicoplanin, linzolid, and chloramphenicol. ${ }^{6}$ Molina et al, reported that isolated organisms were sensitive to nitrofurantoin and cefoperazone. ${ }^{17}$ As a comparison with a study done by Abdullah and Al-Mosleh, which concluded that most sensitive antibiotic, in bacteriuric pregnant women were gentamycin and Amoxicillin-Clavulanate. ${ }^{7}$ Akerele et al, found that most prevalent antimicrobial were ceftazidine $81.6 \%$, Amoxicillin-Clavulanate $71.4 \%$, nitrofurantoin $61 \%$ and gentamycin $57.9 \% .{ }^{18}$ Oladeinde et al, found that fluroquinolones were the most effective antibacterial agents. ${ }^{19}$ The choice of antibiotic should be based on urine culture, stage of gestation, maternal clinical data and the characteristics of the antibiotic. ${ }^{20}$

\section{CONCLUSION}

Urine culture for asymptomatic bacteriuria should be the standard of care for evaluation of pregnant patient during antenatal care as regard presence or absence of UTI. Regular antenatal care and improving educational level of patients contribute in reducing obstetric morbidity resulting from undiagnosed or undertreated UTI. Further studies are recommended to choose suitable time for repeating screening for ASB in pregnant females to avoid missing new cases and detecting possible preventable risk factors for such condition.

\section{Funding: No funding sources}

Conflict of interest: None declared

Ethical approval: The study was approved by the Institutional Ethics Committee

\section{REFERENCES}

1. Jayalakshmi J, Jayaram VS. Evaluation of various screening tests to detect asymptomatic bacteriuria in pregnant women. Indian $\mathbf{J}$ Pathol Microbiol. 2008;51(3):379-81.

2. Uncu Y, Uncu G, Esmer A, Bilgel N. Should asymptomatic bacteriuria be screened in pregnancy? Clin Exp Obstet Gynecol. 2002;29:281-5.

3. Khan AU, Zaman MS. Multidrug resistance pattern in urinary tract infection patients in Aligarh India.Bio Med Research. 2006;17:17.

4. Amiri FN, Rooshan MH, Ahmady MH, Soliamani MJ. Hygiene practices and sexual activity associated with urinary tract infection in pregnant women. East Mediterr Health J. 2009;15(1):104-10.

5. Rouse DJ, Andrews WW, Goldenberg RL, Owen J. Screening and treatment of asymptomatic bacteriuria of pregnancy to prevent pyelonephritis: a costeffectiveness and cost-benefit analysis. Obstet Gynecol. 1995;86(1):119-23.

6. Goyal A, Srivastava N, Goyal S. Prevalence of asymptomatic urinary tract infections in the three trimesters of pregnancy. Int J Curr Microbiol App Sci. 2010;1:110-7.

7. Abdullah A, Al-moslih M. Prevalence of asymptomatic bacteriuria in pregnant women in Sharjah, United Arab Emirates. Eastern Mediterranean Health J. 2005;11:1045.

8. Smaill F, Vazquez JC. Antibiotics for asymptomatic bacteriuria in pregnancy. Cochrane Database Syst Rev. 2007;18:CD000490.

9. Nicolle LE. Asymptomatic bacteriuria: review and discussion of the IDSA guidelines. Int J Antimicrobial Agents. 2006;28S:S42-S48.

10. Hooton TM. The epidemiology of urinary infection and the concept significant bacteriuria. Infection. 2003;(Supp12):S40-3.

11. Felice D, Garingalo-Molina. Asymptomatic bacteriuria among pregnant women. Overview of Diagnostic Approaches. Phil J Microbiol Infect Dis. 1999;29(4):177-86.

12. Veri E, Chia P, Griffith D. Bacteriuria in pregnancy: a comparison of Bangaladeshi and Caucasian women. Int Urogynecol J Pelvic floor Dysfunction; 1997;8:812. 
13. Kennedy E. Pregnancy, urinary tract infections. eMedicine (onlinejournal) (2001). Available at: hup://www.ernedicine.com/ emerg/topic485.htm.

14. Labi AK, Yawson AE, Ganyaglo GY. Prevalence and associated risk factors of asymptomatic bacteriuria in antenatal clinc in alarge teaching hospital in Ghana. Ghana Med L. 2015;49(3):154-8.

15. Akinloye O, Ogbolu DO, Akinloye OM. Asymptomatic bacteriuria of pregnancy in Ibadan, Nigeria: a re-assessment. $\mathrm{Br} \mathrm{J}$ Biomed Sci. 2006;63:109-12.

16. Ayoyi AO, Kikuvi G, Christine B. Prevalence, aetiology and antibiotic sensitivity profile of asymptomatic bacteriuria isolates from pregnant women in selected antenatal clinic from Nairobi, Kenya. The Pan African Medical J. 2017;26:41.

17. Molina R, Molina T, González E. association between asymptomatic bacteriuria and spontaneous preterm birth, Ginecol Obstet Mex. 2008;76(8):454-60.
18. Akerele J, Abhulimen P, Okonofua F. Prevalence of asymptomatic bacteriuria among pregnant women in Benin City, Nigeria. J Obstet Gynaecol. 2001;21:1414.

19. Oladeinde BH, Omoregie R, Oladapo B. Asymptomatic urinary tract infection among pregnant women receiving antenatal care intraditional birth home in Benin city, Nigeria Ethiop J Health Sci. 2015;25(1):3-8.

20. Grio R. Asymptomatic bacteriuria in pregnancy: adiagnostic and therapeutic approach. Panminerva Med. 1994;36:195-7.

Cite this article as: Badran E, Abbas AM, Kamel M, Abdelrahman M, Youssef A, Youssef M. Prevalence of asymptomatic bacteriuria among low risk pregnant women attending antenatal care clinic in tertiary hospital: a cross-sectional study. Int J Reprod Contracept Obstet Gynecol 2019;8:2742-7. 